\author{
Military Technical College \\ Kobry El-Kobbah, \\ Cairo, Egypt.
}

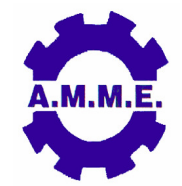

\title{
OIL REGIME MONITORING IN HELICAL GEARS USING ACOUSTIC EMISSION
}
$15^{\text {th }}$ International Conference on Applied Mechanics and Mechanical Engineering.

\author{
M. Hamel*, A. Addali* and D. Mba*
}

\begin{abstract}
Gear lubrication is critically important to maintaining the integrity of operating gears, the lubricant also protects asperity contact at the gear mesh thereby protecting the gears from a deterioration process and surface failures. In this paper, the investigation was centred on the application of the acoustic emissions (AE) technology for monitoring the influence of oil film thickness variation on gear contact and characterising the oil lubrication regimes in helical gear mesh. This investigation employed a back-to-back gearbox test-rig with oil-bath lubrication. The results have demonstrated a clear relationship between $\mathrm{AE}$ activity, operating temperature and specific film thickness. The findings encourage the use of $A E$ techniques to detect and quantify the lubrication regimes during gear meshing.
\end{abstract}

\section{KEY WORDS}

Acoustic Emission, helical gears, specific film thickness, oil regimes, condition monitoring. 


\section{INTRODUCTION}

Acoustic Emission (AE) is defined as a physical phenomenon occurring within and/or on the surface of materials whereby spontaneous elastic energy is released in the form of transient elastic waves which cover a broad frequency range, typically from $20 \mathrm{kHz}$ to $1 \mathrm{MHz}$ (outside the range of human hearing) [1,2]. The use of $A E$ for machine condition monitoring has been developing for nearly 50 years and the application of $\mathrm{AE}$ to monitoring a range of rotating machines has been recently reviewed by Mba and Rao [3]. They report that the growth in the use of $A E$ has been in its applications to leaks in mechanical seals and bearings and reciprocating machines including impacts and asperity contact. The big disadvantage of $A E$ is the severe attenuation across interfaces and the rapid attenuation of $A E$ in liquids and gases. A major advantage of $A E$ is its ability to detect the onset loss of mechanical integrity, where it performs much better than vibration monitoring.

\section{Application of Acoustic Emission to Health Monitoring of Gear Systems}

The application of Acoustic emission to the diagnosis and prognosis of gearbox faults is still relatively new. Boness et al., $[4,5]$ investigated the application of AE to both sliding and rolling conditions and found that asperity contact generated AE. This research is an attempt to further the understanding of how the operation of both helical and spur gears generate AE and extend present knowledge as reported in [67] that the principal sources are interactions between the surface roughness of the two gear surfaces due to their relative motion. Helical and spur gears undergo combined rolling and sliding on both sides of the pitch point, and pure rolling at the pitch point. However, due to the geometry of the helical gears, the pitch point during gear mesh is not passed at the same time along the width of the gear like during spur gear mesh, i.e., pitch point contact for the helical gear mesh is progressive.

The operating life of gears is determined by the ratio between the oil film thickness and the combined surface finishes of the parts, this ratio is known as (lambda ratio $\lambda$ ), which is vital for maintaining mechanical integrity. Recommended values for $\lambda$ have been published but the actual value is difficult to determine during operation. EHL studies have shown that $\lambda$ is predominantly determined by temperature, load, surface roughness and speed of the meshing gears $[8,9,10]$. Because $\lambda$ changes with change in any or all the parameters listed, the level of contact between the surface roughness during gear meshing will also vary.

Raja and Mba [1] observed AE was more sensitive to changes in specific film thickness under combination of rolling and sliding (spur gear) as compared to pure rolling (helical gear).and relationship between load, speed and $A E$ for both spur and helical gears was established. Furthermore the variation in AE levels during helical gear mesh is speculated to be attributed to not only the influence of asperity levels but also to the variation in the contact length during meshing.

\section{Acoustic Emission and Film Thickness}

Ben Abdallah and Aguilar [11] used a ball-on-cylinder lubrication test machine with a fixed, stationary ball sliding over a flat ring attached to a rotating cylinder, to investigate how the sound emitted depended on friction and wear properties. 
Included in the investigation was dry sliding contact lubricated with pure grease and simulated contamination by introducing small glass particles.

The speed of the cylinder (sliding speed of the ball) was the parameter of major interest and it was found that for dry contact: sliding contact generated a continuous $A E$ waveform, the RMS voltage of the AE signal produced by the ball sliding over the ring was a good measure of the coefficient of friction $(\mu)$ and that - vice versa - the RMS of the AE signal could be used to give a good estimate of $\mu$.

Jie and Drinkwater [12] used an ultrasonic technique to measure the thickness of lubricating films for the rolling element of a ball bearing type 6016. The results obtained were in good agreement with those produced by EHL theory over the range $0.3-1.0 \mu \mathrm{m}$ for radial loads greater than $2.5 \mathrm{kN}$ but shaft speeds less than 200rpm $(3.3 \mathrm{~Hz})$. Ultrasonic measurements suffer from a number of limitations, including: the pulse repetition rate will limit the number of measurement points; the ultrasonic beam does not focus at a point but over a small area and so gives an average value over that area. However it was clearly demonstrated that ultrasonic measurement has the potential for monitoring the thickness of lubricant films in industrial applications.

Toutountzakis and Mba, and Toutountzakis et al., [13,7] have used AE for the experimental investigation of gear defects and their diagnosis. They showed that $A E$ monitoring of the health of gears was a useful tool that would allow monitoring for developing defects in gears externally, from a sensor on the bearing casing. Tan, and Mba [14] noted that for isothermal conditions the imposed load had a minimal effect on the RMS level of the AE signal, but that speed had a significant effect. They confirmed that for rolling contact the level of the $A E$ signals depended on the speed of rotation of the gears and that $A E$ transients were found at the gear mesh frequency. The RMS value of the $A E$ signal was also dependent on the film thickness. The relative proportions of rolling and sliding contact strongly affected the overall level of the AE signal.

Raja and Mba [15] extended the previous work into the generation of $\mathrm{AE}$ as a function of $\lambda$ using helical and spur gears made of $045 \mathrm{M} 15$ steel without any heat treatment, in a standard back-to-back oil bath lubricated gearbox, powered by a $1.1 \mathrm{~kW}$ motor. It was found that the value of $\lambda$ clearly and directly influenced the level of the AE signal for both types of gears (Inversely proportional).

Babak and Mba [16,17] assessed the ability of $A E$ to identifying specific defects seeded into helical (214M15) steel test gears. The gearbox test rig employed was the same back-to-back arrangement as used in [15] and operated at a speed of $11.5 \mathrm{~Hz}$ (690 rpm). Mobil gear 636 oil was the lubricant used in the oil bath. They conclude that the AE waveform could be used to identify the seeded defects. They also concluded that the measured AE RMS levels were useful for the identification of the seeded faults than vibration measurement made with an accelerometer situated on the bearing pedestal. However Toutountzakis et al. [7] using a similar test procedure found this was not the case for spur gears.

In this paper, the investigation was centred on the application of the acoustic emissions (AE) technology for monitoring the influence of oil film thickness variation on gear contact and characterising the oil lubrication regimes in helical gear mesh. 


\section{EXPERIMENTAL SETUP AND PROCEDURE}

\section{Experimental Setup}

This investigation employed a back-to-back gearbox test-rig with oil-bath lubrication as described in [15, 16, and 17], see Figure 1a. Gear data and operating conditions are given in Table 1. Tests used gear surface finishes of $2.5 \mu \mathrm{m}$ and Mobil gear 636 lubrication (data on the lubricant is given in Table 2). The gearbox could be run at six different torque loadings $(60,120,180,250$ and $370 \mathrm{Nm})$ and speed of $620 \mathrm{rpm}$. The AE sensor used was a wide-band WD model from Physical Acoustics Corporation with operating frequency range from $100 \mathrm{kHz}$ to $1 \mathrm{MHz}$.

The temperature was reduced by injecting liquid nitrogen onto the wheel gear through a $5 \mathrm{~mm}$ diameter steel tube, see Figure 1b. Temperature measurements of the gear metal and lubricant bath were made with $\mathrm{K}$-types thermocouples, rated from $-60^{\circ} \mathrm{C}$ to $+850^{\circ} \mathrm{C}$, see Figure $2 \mathrm{a}$. The cables from the $\mathrm{AE}$ sensor and thermocouples were fed through the shaft to a silver contact slip ring, Figure $2 \mathrm{~b}$. AE signal loss via slip ring (Appendix D) was measured to be less than $5 \%$ in terms of maximum amplitude. The signal from the sensor was then pre-amplified at $40 \mathrm{~dB}$.

The Data Acquisition System (DAQ) consisted of the 'AE Win' system which is capable of calculating the acoustic emission (AE) activity in-situ. The 'Mistras' system used and captured the raw waveform.

\section{Experimental Procedure}

This investigation was completed using a 2.5 micron surface finished helical gear and Mobil gear 636 lubrication. Gear data, operating conditions and lubricant properties are shown in Appendixes A, B, C and D. A load of $370 \mathrm{Nm}$ was used for the purpose of this stage of the test.

The gearbox ran for a total time of about 4 hours at $370 \mathrm{Nm}$ load and speed $620 \mathrm{rpm}$ until the temperature stabilized $\sim 40^{\circ} \mathrm{C}\left(-/+1^{\circ} \mathrm{C}\right.$ over an hour). To remove heat and reduce the temperature, liquid nitrogen was sprayed onto the wheel through a $5 \mathrm{~mm}$ diameter steel pipe. The liquid of nitrogen supply was stopped when the temperature of the metal of the gear reached $0^{\circ} \mathrm{C}$. The gearbox was then allowed to run continuously until the temperature stabilized again. This procedure was repeated to ensure more accurate results and reliability. 
Table 1: Gears Dimensions.

\begin{tabular}{|l|c|c|}
\hline Gears Dimensions & Symbol & Value \\
\hline tip diameter, pinion & $\mathrm{d}_{\mathrm{a}}$ & $166.65 \mathrm{~mm}$ \\
\hline base diameter, pinion & $\mathrm{d}_{\mathrm{o}}$ & $150.06 \mathrm{~mm}$ \\
\hline pitch diameter, pinion & $\mathrm{d}$ & $160.65 \mathrm{~mm}$ \\
\hline tip diameter, wheel & $\mathrm{D}_{\mathrm{a}}$ & $226.50 \mathrm{~mm}$ \\
\hline base diameter, wheel & $\mathrm{D}_{\mathrm{o}}$ & $205.97 \mathrm{~mm}$ \\
\hline pitch diameter, wheel & $\mathrm{D}$ & $220.50 \mathrm{~mm}$ \\
\hline gear face width & $\mathrm{f}$ & $25 \mathrm{~mm}$ \\
\hline center distance & $\mathrm{C}$ & $190.58 \mathrm{~mm}$ \\
\hline center distance & $\mathrm{t}$ & $51 \mathrm{teeth}$ \\
\hline base helix angle & $\sigma_{0}$ & $17.75^{\circ}$ \\
\hline Normal module & $\mathrm{mn}$ & 3 \\
\hline
\end{tabular}

Table 2: Lubricate Specifications.

\begin{tabular}{|c|c|c|}
\hline \multicolumn{3}{|l|}{ Mobilgear 636} \\
\hline cSt @ 40ㄷ C & 150 & 680 \\
\hline cSt @ 100ㄷ & 15.8 & 39.2 \\
\hline Viscosity Index, ASTM D 2270 & 98 & 90 \\
\hline Pour Point, ${ }^{\circ} \mathrm{C}, \mathrm{ASTM}$ D 97 & -27 & -9 \\
\hline Flash Point, ${ }^{\circ} \mathrm{C}, \mathrm{ASTM}$ D 92 & 245 & 285 \\
\hline Density @15.6으 C, ASTM D 4052, kg/l & 0.89 & 0.91 \\
\hline Timken OK Load, ASTM D 2782, lb & 65 & 65 \\
\hline \multicolumn{3}{|l|}{ 4-Ball EP test, ASTM D 2783: } \\
\hline Weld Load, $\mathrm{kg}$ & 250 & 250 \\
\hline Load Wear Index, kgf & 48 & 48 \\
\hline FZG Scuffing, DIN 51534, A/8.3/90, Fail Stage & $12+$ & $12+$ \\
\hline Rust protection, ASTM D 665, Sea Water & Pass & Pass \\
\hline Copper Strip Corrosion, ASTM D130, 3 hrs@100ㅇ C & $1 \mathrm{~B}$ & $1 \mathrm{~B}$ \\
\hline $\begin{array}{l}\text { Demulsibility, ASTM D 1401, @ 54ํ C Time to 3ml } \\
\text { emulsion, minutes @ 82으 C }\end{array}$ & 30 & 30 \\
\hline
\end{tabular}

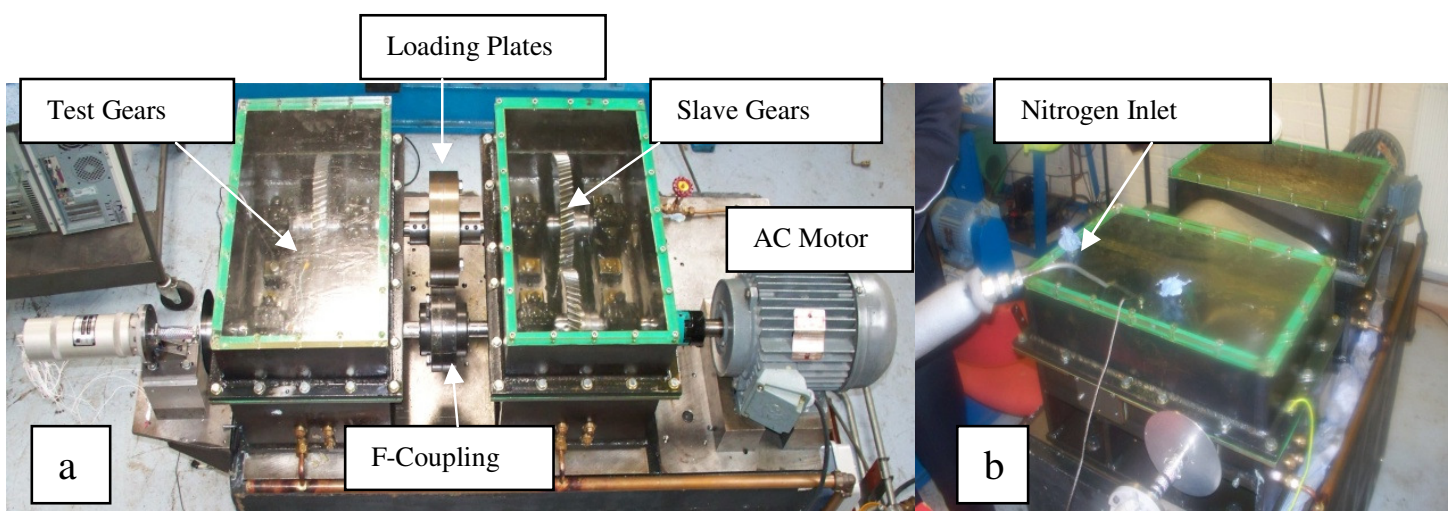

Figure 1: back-to-back gearbox; a) arrangement of the test-rig, b) nitrogen entrance 


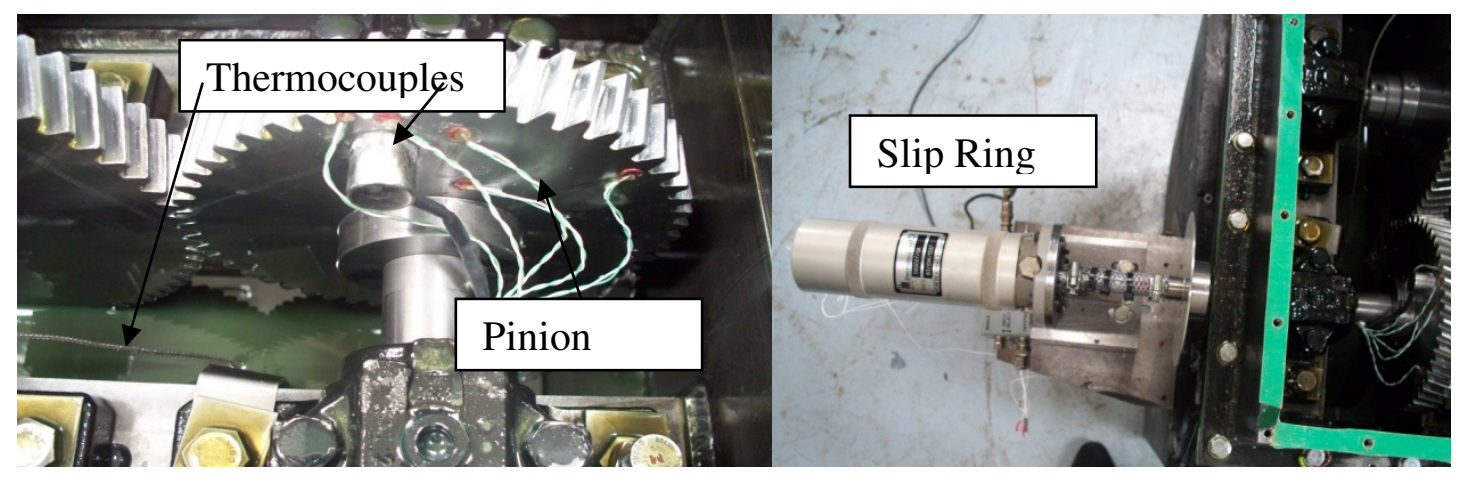

(a)

(b)

Figure 2: Slip Ring and Thermocouples.

\section{RESULTS AND DISCUSSION}

For the purpose of this investigation, AE RMS 1values were recorded. From the measured temperature and by using MacCoull's Eq. (3) [18], viscosity values were determined. Based on measured gear and oil temperature and on the assumptions that the load acts along the line of action and pitch errors are very small, the film thickness was calculated using equations of Dowson and Higginson [19]. Specific film thickness $(\lambda)$ for both oil and gear metal was obtained by calculating oil film thickness and dividing it by composite surface roughness $\left(\sigma_{\mathrm{rms}}\right)$, by using the equation.

$$
\text { Specific film thickness } \quad \lambda=\boldsymbol{h}_{\min }=\frac{h}{a_{\text {rms }}}
$$

where $\boldsymbol{h}$ is oil film thickness and $\boldsymbol{\sigma}_{\mathrm{rms}}$ is a measure of the composite RMS roughness of the two surfaces in frictional contact.

Figures (3a) and (3b) show the change in AE RMS as a function of specific film thickness $(\lambda)$. The AE RMS decreased with the increase of specific film thickness $(\lambda)$ calculated with both the gear metal and oil bath temperature as shown in Figure (3a). The AE RMS reached its lowest value when specific film thickness $(\lambda)$ was a maximum. During the cooling phase from the point when nitrogen was introduced into gear rig, there was an immediate slight increase in AE activity (see Figure (3a)) which continued even as the temperature of gear and oil were decreasing. It is believed that this feature can be attributed to the change in the micro-structure of gear materials with the impact of the liquid nitrogen on the metal of the gears and the local temperature dropped rapidly. It could also be attributed to "oil drag", the friction generated by the oil between gears (region circled by black dotted line in Figure 3a). However, once the gear temperature reached $0 \mathrm{C}^{\circ}$ the nitrogen supply stopped and the temperature of oil lubricant and gear metal gradually returned to the initial operating levels. This stage corresponded to increase in AE activity as specific film thickness $(\lambda)$ decreased; see Figure (3a). 

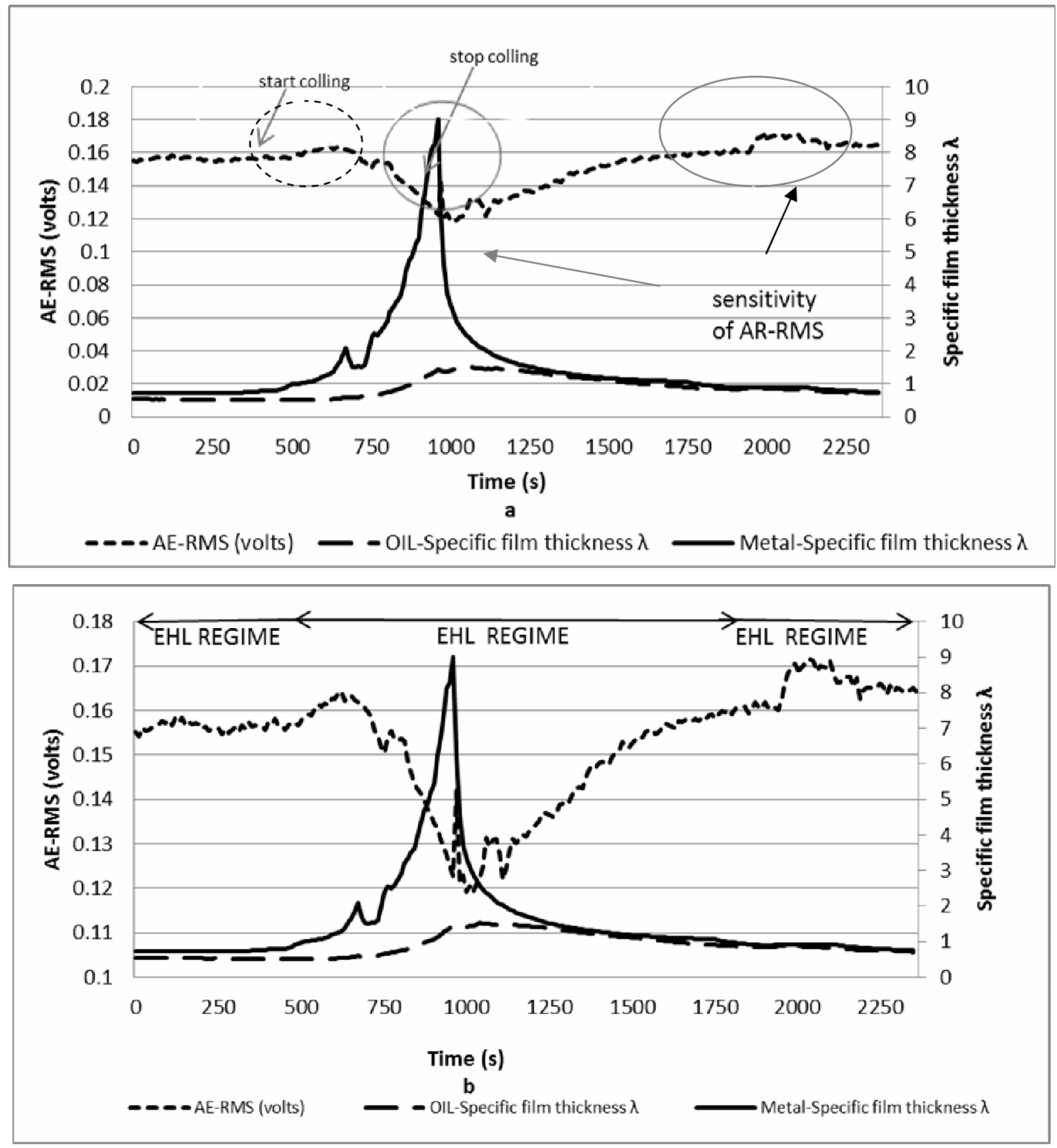

Figure 3: AE RMS and specific film thickness $(\lambda)$,

(a) $A E$ and $(\lambda)$ for all process and (b) AE and $(\lambda)$ at min temperature.

It is worth mentioning that a frozen oil lubricant mist was produced as a result of low temperatures of the liquid nitrogen. This frozen mist entered the space, and was crushed, between the gears. This crushing process affected the AE and resulted in unreliable results as shown by the green circles in Figure (3a). Figure (3b) is an enlarged view of these circles.

Raw waveforms were captured every 30 seconds during the tests. A sample of the AE waveforms observed when the specific film thickness $(\lambda)$ was increasing is shown in Figures (4) and (5). These figures also show the plots for temperature and AE with time. In Figure 4, there are five instances, A, B, C, D and E. Figure (5) shows the corresponding $A E$ waveforms. It was noted that for normal operating conditions $(A)$, 


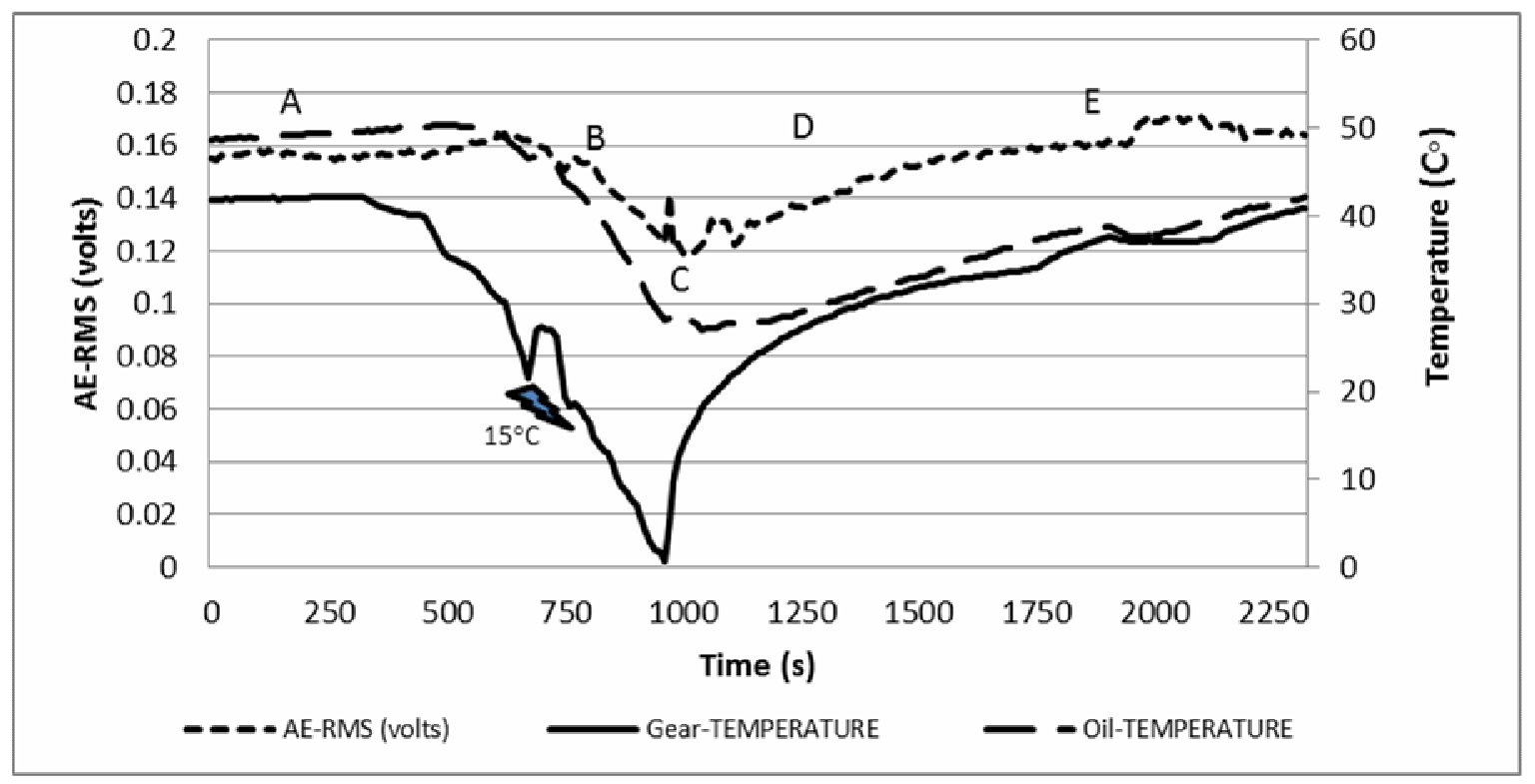

Figure 4: $A E$ and temperatures of gear metal and oil with time.

the $A E$ waveform showed transient bursts interfering with a continuous type waveform where the rate of generation of the transient bursts corresponded to the gear mesh frequency and a transient burst was associated with gear mesh and, possibly to asperity contact. At the minimum temperature, where specific film thickness $(\lambda)$ was a maximum, AE waveform (C) was significantly reduced in amplitude and it was noted that the transient bursts were hardly distinguishable from the continuous emissions. The reduction in amplitude is attributed to the reduced asperity contact at the mesh as result of the increased film thickness.

\section{CONCLUSIONS AND FUTURE WORK}

What has been studied and tested can be summarised in the following points:

- The current research program has demonstrated a clear relationship between AE activity, operating temperature and specific film thickness.

- The results obtained encourage testing the use of $A E$ techniques to detect and quantify the lubrication regimes during teeth meshing.

- Results confirm that asperity contact is an important source of AE activity.

- The use of liquid nitrogen to reduce oil temperature, generated significant $A E$ activity, but that $A E$ activity decreased rapidly when the temperature reached about $15^{\circ} \mathrm{C}$, furthermore $\mathrm{AE}$ activity was activated by dropping lubricant on a dryrunning gear.

- The outcomes of this research can contribute to a better and deeper understanding of lubrication film classifications and their effects on gear performance and service life efficiency.

- It is believed that the established relationships could be used to quantify oil film parameters through measurement of $A E$ activity. 


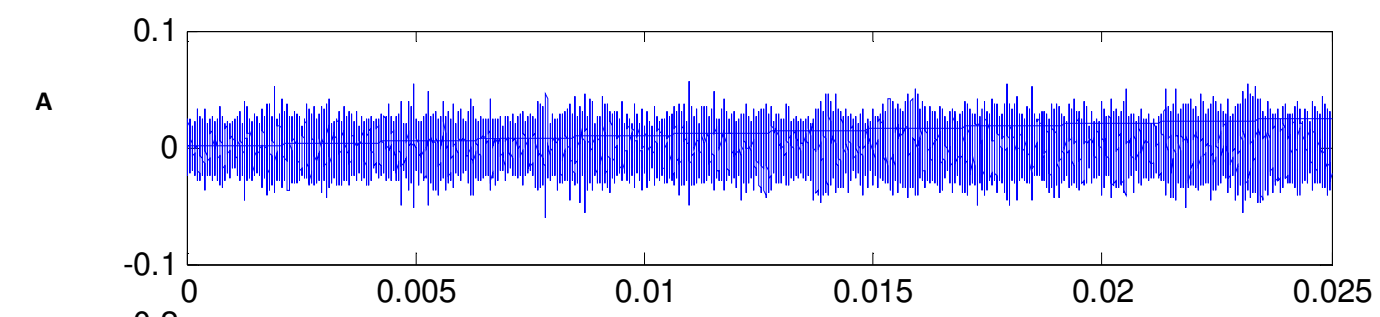

B

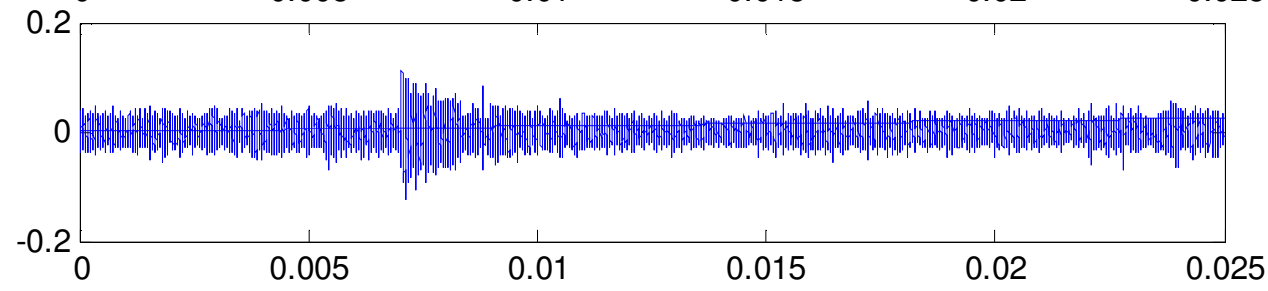

C

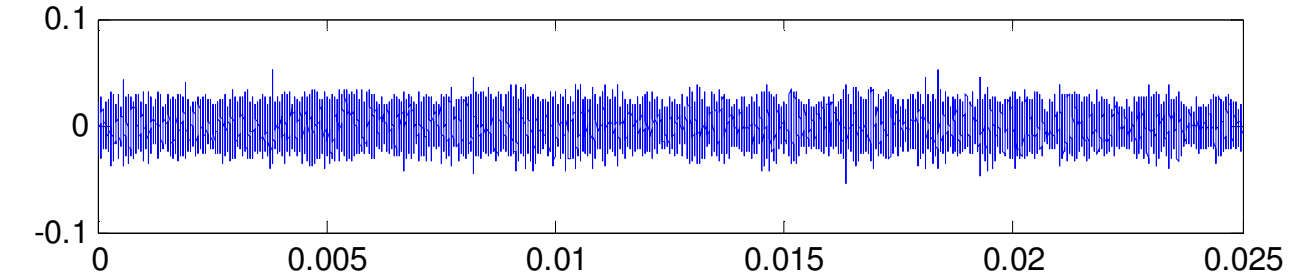

D
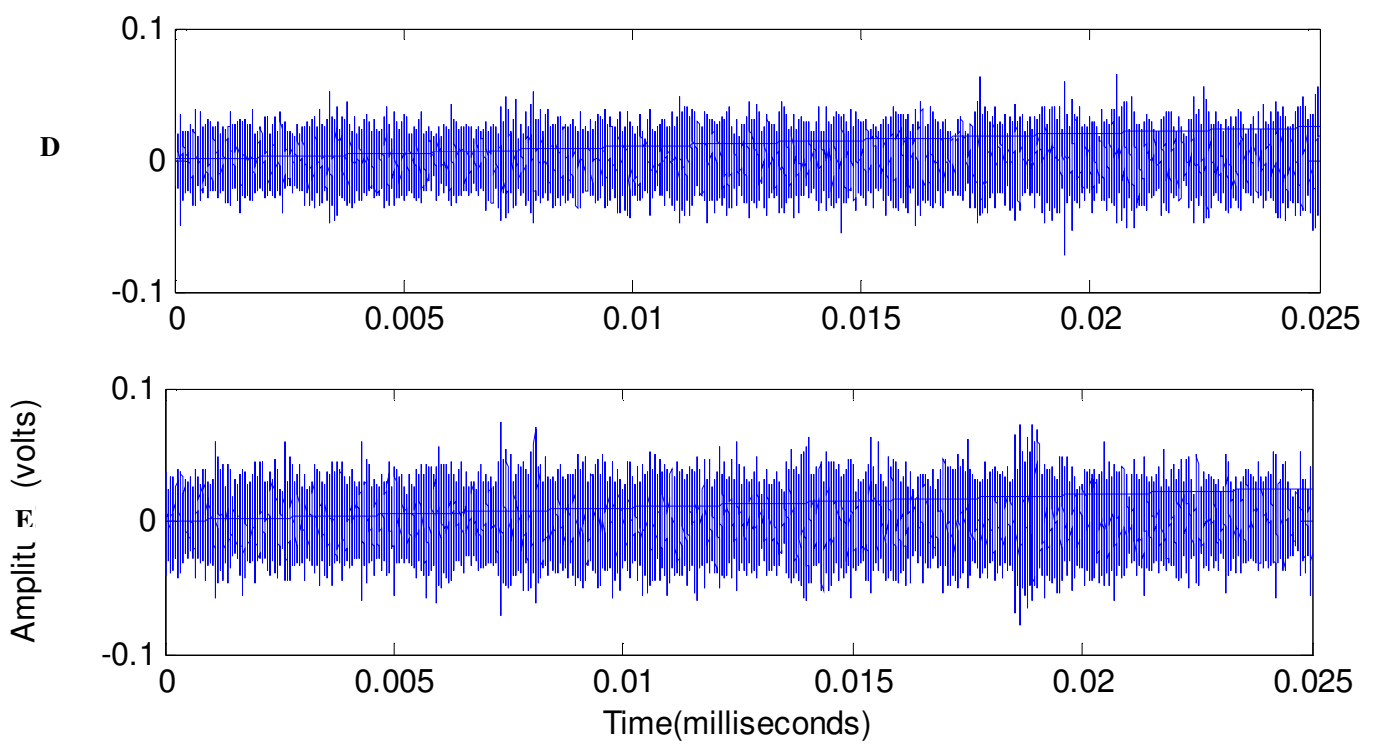

Figure 5: AE waveforms during first test: A, B, C and D as in Figure 4.

\section{REFERENCES}

[1] RajaHamzah, R. and Mba, D. (2009) The influence of operating condition on acoustic emission during meshing of helical and spur gear, Tribology Int., Vol. 42, pp. 3-14.

[2] Miller, R.K. and Mclntire, P. (1987) Acoustic emission testing. Nondestructive Testing Handbook, 2nd ed. Vol. 5, American Society for Nondestructive Testing. 
[3] Mba, D. and Rao, R. (2006) Development of acoustic emission technology for condition monitoring and diagnosis of rotating machines: bearings, pumps, gearboxes, engines and rotating structures. Shock and Vibration Digest, Vol. 38(1), pp. 3-16.

[4] Bones, R.J. Wear studies using acoustic emission techniques, Tribology Int., October 90, Vol. 23, No 5.

[5] Bones, R.J. and McBride, S.L. (1991) Adhesive and abrasive wear studies using acoustic emission techniques, Wear, Vol 149 pp41-53.

[6] Tan, C.K. and Mba, D. (2005) Identification of the acoustic emission source during a comparative study on diagnosis of a spur gearbox. Tribol Int. Vol. 38 pp. 469-80.

[7] Toutountzakis, T., Tan, C.K. and Mba, D. (2005) Application of acoustic emission to seeded gear fault detection. NDT\&E Int., Vol, 38, pp.27-36.

[8] Dowson, D. (1995) Elastohydrodynamics and microelastohydrodynamic lubrication. Wear. Vol. 190, pp.125-138.

[9] Dowson, D. and Higginson, G. R. (1977) Elastohydrodynamic Lubrication. $1^{\text {st }}$ edition. Pergamon Press. Oxford, UK.

[10] Dowson, D. and Ehret, P. (1999) Past, present and future studies in elastohydrodynamics. J Eng Tribol, I Mech E, Part J Vol 213 pp317-333.

[11] Ben Abdallah, H.S. and Aguilar, D.A. (2008) Acoustic Emission and Its Relationship with Friction and Wear for Sliding Contact. Tribology Trans. Vol 51pp738-747.

[12] 1ie Zhang and Drinkwater,B.W. Acoustic measurement of lubricant-film thickness distribution in ball bearings. J. Acoustic. Soc. Am., Vol. 119, No. 2, February 2006.

[13] Toutountzakis, T. and Mba, D. (2003) Observation of acoustic emission activity during gear defect diagnosis. NDT\&E Int. Vol. 36 pp 471.

[14] Tan, C.K. and Mba, D. (2005) Experimentally established correlation between acoustic emission activity, load, speed and asperity contact of spur gears under partial elastohydrodynamic lubrication. Proc IMechE Vol. 219 Part J: Engineering Tribology.

[15] Raja Hamzah RI, Mba, D. (2007) Acoustic emission and specific film thickness for operating spur gears. J Tribol Vol 129(4) pp. 860.

[16] Eftekharnejad, B and Mba, D. (2008)Acoustic emission signals associated with gears, Applied Acoustics Vol. 70 pp. 547-555.

[17] Eftekharnejad, B. and Mba, D. Seeded fault detection on helical gears with acoustic emission, Applied Acoustics 70 (2009) 547-555.

[18] Alexander, D.L. (1992) The viscosity of lubricants. Lubrication. Vol. 78(3).

[19] Dowson, D. and Higginson, G. R. (1977) Elastohydrodynamic Lubrication. I ${ }^{\text {st }}$ edition. Pergamon Press. Oxford, UK. 